\title{
Suggestions for Reviewing Manuscripts
}

\author{
Andrei V. Alexandrov $^{a}$ Michael G. Hennerici ${ }^{b}$ Bo Norrving ${ }^{c}$ \\ ${ }^{a}$ Comprehensive Stroke Center, University of Alabama Hospital, Birmingham, Ala., USA; \\ ${ }^{b}$ Department of Neurology, University of Heidelberg, Mannheim, Germany; 'Department of Neurology, \\ University Hospital, Lund, Sweden
}

\section{Key Words}

Peer review $\cdot$ Ethics $\cdot$ Validity

\begin{abstract}
Background: Scientific reviewing is a voluntary process to determine if a manuscript deserves publication. REVIEW means: Responsibly Evaluate, Verify and Improve the manuscript, Educate the authors and editors, and Weigh your expert opinion against the submitted work. Provide your review in a respectful, unbiased and timely manner. Review Methods: Make sure editors know about your willingness to review and your particular area(s) of expertise. If you find yourself in a conflict of interest, decline to participate in reviewing. If you accept, complete reviews on time. Determine and rate (1) the methodological validity, (2) originality, (3) significance of findings, (4) the style and clarity of presentation and (5) the findings' interest to the readership of the journal for which you are asked to review a manuscript. Specifically evaluate (6) if the results support any claims or conclusions made and, most importantly, (7) if the abstract correctly reflects the full content of a manuscript. Summarize your review in specific comments to the authors. Make recommendations whether to accept, revise or reject the manuscript to the editor only. Review Results: Start with a brief summary of the manuscript's subject, strengths and key findings/claims. Present your specific criticisms and suggestions in numbered lists for the authors to address. Never use demeaning and offensive words or sarcasm since, in the first place, this reflects upon your own ethics and integrity as well
\end{abstract}

as upon the journal's. Use a constructive tone, and if you see any deficiencies, educate the authors in a respectful manner so that, even if a manuscript is rejected, they will learn from you, improve the manuscript or conduct a better study in the future. Also include ratings from 1 to 7 in your comments to the authors, as far as they are relevant and may explain your final decision. Conclusions: Judge others as you would like to be judged yourself. We hope these suggestions serve to help new reviewers and refresh the willingness of battlehardened veterans to continuously serve the medical literature.

Copyright $\odot 2009$ S. Karger AG, Basel

For with the judgment you pronounce you will be judged, and with the measure you use it will be measured to you. Matthew 7:1-3

But who are the judges?! Aleksandr Griboedov (1794-1829)

\section{Introduction}

It is an understatement to note that reviewing is a touchy subject. Given the wide range of publications subject to review, we hope the following suggestions for reviewing are understood as guidelines. Although many reviewers have worked at a high level from the beginning, the steady increase in submissions forces them to plan and become a bit more focused. We also provide these suggestions for future referees of scientific writing.

\section{KARGER \\ Fax +41613061234 \\ E-Mail karger@karger.ch}

www.karger.com (c) 2009 S. Karger AG, Basel

$1015-9770 / 09 / 0283-0243 \$ 26.00 / 0$

Accessible online at:

www.karger.com/ced
Dr. A.V. Alexandrov

Comprehensive Stroke Center

UAB Hospital RWUH M226, 619 19th Street South

Birmingham, AL 35249 (USA)

Tel. +1 205934 2401, Fax +1 205975 6785, E-Mail avalexandrov@att.net 
If you are thinking about becoming a reviewer, this paper will introduce you to this process and outline some of the - often unspoken and implied - principles. Senior members of the scientific community often pass invitations for review to their junior colleagues. Read this paper if you are faced with your first-time invitation and do not know where to start or how to express your opinion. If you are a seasoned reviewer, you may find some validation of what you are doing or some suggestions to improve your reviews. In any case, reviewing is an integral part of scientific progress, and we should all contribute to its quality. The publication of research results - whether positive, neutral or negative - is an ethical imperative [1]. Reviewers must always seek ways to improve the manuscript, help the editors and readership to understand its importance and generalizability [2], and to determine if it reaches the level of priority to be published in a given journal.

In this spirit we propose the time-honored term 'REVIEW' as an acronym for: Responsibly Evaluate and Verify the findings and statistics as much as possible, Improve the manuscript, Educate the authors and editors, and Weigh your expert opinion against the submitted work. Reviewers benefit through this process by learning and becoming better scientists themselves. Reviewers are often challenged to deal with new thinking, novel data or innovation, and they have to critically rethink the process that the authors have gone through and judge the validity of their findings.

\section{Review Methods}

Editors send invitations that inform potential reviewers about the manuscript title and contents of the abstract so that prospective reviewers can decide if the manuscript falls within their areas of expertise. Citing your particular area(s) of expertise saves editors time and spares you the disappointment of receiving requests for subjects that bring you to decline an invitation.

Any conflict of interest (COI) difficult for the editors to assess in advance is ample reason to decline to participate in a review. Conducting your own research or being interested in the same area as the authors of a manuscript does not constitute a COI. What constitutes a COI is if you collaborate, or have recently collaborated, with the authors in research projects or if you, in your own judgment, are unable to take a balanced and unprejudiced view.

Authors can list suggested reviewers as well as those to whom the manuscript should not be sent at all. This yields reviews of a quality similar to those that have been written by reviewers chosen by editors; however, the authors' suggested reviewers were more likely to recommend acceptance $[3,4]$.

If you already reviewed a manuscript in the same or a substantially unchanged form for another journal, please inform the editor in advance and ask for his recommendation on how to proceed. A copy of the previous review is sometimes more suitable than a second review.

If you agreed to review a manuscript, the authors much appreciate the timely completion of the assignment, as you would do as an author awaiting a similar decision.

After considering the manuscript's appropriateness to a given journal, determine and rate these self-explanatory aspects:

(1) methodological validity,

(2) originality,

(3) significance of findings,

(4) style and clarity of presentation,

(5) interest to readership,

(6) if results support claims or conclusions, and

(7) if the abstract correctly reflects the full content of the manuscript.

Start with the determination of the findings' methodological validity, novelty and significance. These tasks contribute to your learning since, as you critically evaluate methods and analyses, you may 'dig in' deeper into specific methodologies, statistics, etc. Stay on top of current developments in your area of expertise. We often look up sources referenced in manuscripts as well as other papers that may have eluded the authors' attention. This helps you to gain a deeper understanding of the study's subject and of the progress made in the area, and to offer any insights useful to the authors in revising the manuscript. Approach each manuscript with an open mind. Even if you think you know most of the research in this area, you may occasionally be surprised by an unconventional approach. Even if you disagree with the authors a priori, try to objectively evaluate the strength of the data and the validity of their conclusions.

Specifically evaluate if the results support any claims or conclusions and if the abstract correctly reflects the content of the manuscript. Summarize your review results in specific comments to the authors and provide a separate recommendation to the editor whether to publish this manuscript or not.

Most journals, including Cerebrovascular Diseases, support a web-based review process with forms that reviewers have to fill out. These forms often have structured questions that help editors to streamline the pro- 
cess and provide some journals with quantifiable results of your review.

Your suggestions about analytic methods and about statisticians with expertise in the study's subject are always appreciated. In fact, a study suggested that reviewers who had been trained in epidemiology and biostatistics might provide better quality reviews as judged by the authors [5]. Younger reviewers tended to provide higher quality reviews $[5,6]$, and those spending up to $3 \mathrm{~h}$ reviewing a manuscript [5]. However, there are no strong predictors overall to identify those who will provide higher quality reviews, and the whole process remains ill defined [6]. Contrary to expectations, an attempt to improve the review skills in a short workshop for active reviewers did not yield any desirable results [7].

The comments to the authors are the most important part of the review process. Assume you write to a colleague who will find your name at the end of the review, even though our reviewers are not mentioned that way. Some authors often believe they recognize certain compositional styles and assume the reviewer's name, even in error!

Be honest and communicate without humiliating the authors, no matter how wrong or insignificant the results are in your opinion. Your comments, first of all, reflect upon you and the journal which asked you to review the manuscript. Acceptance or rejection is a recommendation to be communicated to the editors only.

\section{Review Results}

Start your comments to the authors with a brief summary of the manuscript's subject, strengths and key findings/claims. This section shows that you grasped the content of the manuscript and realized its significance. Comment positively on the manuscript'simportance, strengths and generalizability.

The abstract is read more often than the full paper $[8$, 9] so please comment on its clarity.

If the manuscript seems to be in need of revision, present your specific criticisms and suggestions as a numbered list for the authors to address. If the authors attend to all your points of criticism and suggestions, numbering will help you to follow as you read their reply. Use a constructive tone, and if you see any deficiencies, educate the authors in a respectful manner so that, even if a manuscript is rejected, the authors will learn from you, improve it and either submit a better version to another journal or conduct a better study in the future.

Suggestions for Reviewing Manuscripts
Always check if the research question is clearly stated. If not, ask for clarification. Examine the study's methods in detail to verify if the approach taken is valid. Should you feel the need to ask the authors for more information, please indicate if the information has to be inserted in a revision or directed to the reviewer only in a letter of response.

Research has been done on the quality of manuscripts with masked before-and-after-review assessments [2]. The most substantial improvements were seen in the discussion of study limitations, generalizations, use of confidence intervals and the tone of the conclusions [2].

Some standard rewriting is sometimes needed, such as: 'our study showed ...', as well as advice to the authors to lucidly summarize their key findings [10]. Ask the authors to shorten the discussion, if necessary. Discussions (like introductions) are not supposed to be extensive reviews with numerous references [10]. The discussion is also the weakest part of the manuscript, so efforts to prune any digressive and expansive conclusions should be noted.

Most authors anticipate questions about the limitations of their study, but if not, it is useful that they be noted in the review. An analysis of a study's limitations says something about the authors' and reviewers' integrity and scientific approach to the problem. You may suggest to the editor to write a comment or an editorial alongside the accepted manuscript if you feel that the discussion of the limitations, significance or impact needs to be taken further.

For those authors clearly inexperienced in manuscript composition, advice can be found in the literature $[8,9$, 11].

Sad to say, sometimes references are cited erroneously, even at times the key one(s). A tactful note of the error is usually sufficient for the embarrassed author. You are not required to check every reference but a careful look at the sources and foundation for the arguments is a must.

Journals may have blinded and structured review policies $[12,13]$. In this case, follow the instructions. If a journal offers an unblinded review, evaluate the fairness of your contribution to the manuscript as well as any potential bias. Cerebrovascular Diseases and other journals expect that the authors of a manuscript should acknowledge those who contributed to the study (i.e. the list of sites and researchers) and those who were helpful to the authors (i.e. funding agencies, expert consultants and volunteers). It is also prudent to have disclosures of the authors' conflicts of interest [14] so that the study's findings and interpretation can be put into perspective by the

Cerebrovasc Dis 2009;28:243-246 245 
readership (this could be part of the editorial office's responsibilities with blinded reviews). As an unblinded reviewer, you can insist upon a more detailed assessment of contributors and conflicts. Some journals also require the authors to disclose the contribution of each author to the final manuscript, and leading publishers offer criteria for who should be the authors [15].

\section{Final Suggestions}

Partition your review into an introductory section, major comments and minor comments. This way, it is easy for the editor and authors to see where the main problems are and what needs to be done to reach the priority level for publication. If revision is recommended, state that you are willing to look at the manuscript again. In re-reviewing, check if the authors have responded adequately to your comments and if any required changes have been included in the manuscript (and not only in the response to the reviewers). Do not bring up any new is- sues at the time of re-reviewing (unless possibly prompted by the authors' comments); all your pertinent comments on the manuscript should have been made at the time of the first review.

We hope these suggestions serve to help new reviewers and refresh the willingness of those battle-hardened veterans to continuously serve the medical literature.

\section{Acknowledgments}

We are indebted to our colleagues and friends, editors and many experts, whose reviews and decisions we had a chance to read and occasionally disagree with. We are also grateful to the associate editor of Cerebrovascular Diseases, Dr. Jay P. Mohr, an outstanding mentor and accomplished scientific writer, for his insightful comments and encouragement.

This publication is the third installment of a series of papers aiding those involved in scientific reporting, writing and publishing $[8,10]$, and it is meant to be used with other sources available to authors $[9,11,16,17]$ and reviewers (specific instructions can be found on the websites of each journal or in any invitation to review a manuscript).

\section{References}

1 Pearn J: Publication: an ethical imperative. BMJ 1995;310:1313-1315.

$\checkmark 2$ Goodman SN, Berlin J, Fletcher SW, Fletcher $\mathrm{RH}$ : Manuscript quality before and after peer review and editing at Annals of Internal Medicine. Ann Intern Med 1994;121:60-61.

-3 Schroter S, Tite L, Hutchings A, Black N: Differences in review quality and recommendations for publication between peer reviewers suggested by authors or by editors. JAMA 2006;295:314-317.

4 Wager E, Parkin EC, Tamber PS: Are reviewers suggested by authors as good as those chosen by editors? Results of a rater-blinded, retrospective study. BMC Med 2006;4:13.

5 Black N, van Rooyen S, Godlee F, Smith R, Evans S: What makes a good reviewer and a good review for a general medical journal? JAMA 1998;280:231-233.

6 Callaham ML, Tercier J: The relationship of previous training and experience of journal peer reviewers to subsequent review quality. PLoS Med 2007;4:e40.
Callaham ML, Schriger DL: Effect of structured workshop training on subsequent performance of journal peer reviewers. Ann Emerg Med 2002;40:323-328.

8 Alexandrov AV, Hennerici MG: Writing good abstracts. Cerebrovasc Dis 2007;23: 256-259.

9 European Stroke Conference: http://www. eurostroke.com/submission_instructions. html (accessed July 2, 2009).

10 Alexandrov AV: How to write a research paper. Cerebrovasc Dis 2004;18;135-138.

11 International Stroke Conference: Writing good abstracts. 2009. http://strokeconference.americanheart.org/portal/strokeconference/sc/writinggoodabstracts.
12 Justice AC, Cho MK, Winker MA, Berlin JA, Rennie D: Does masking author identity improve peer review quality? A randomized controlled trial. PEER Investigators. JAMA 1998;280:240-242.

13 Schriger DL, Cooper RJ, Wears RL, Waeckerle JF: The effect of dedicated methodology and statistical review on published manuscript quality. Ann Emerg Med 2002;40:334337.

14 Holloway RG, Benesch C: When disclosures are more interesting than the evidence. Stroke 2009;40:e44.

15 Anonymous: Policy on papers' contributors. Nature 1999;399:393.

-16 Pakes GE: Writing manuscripts describing clinical trials: a guide for pharmacotherapeutic researchers. Ann Pharmacother 2001; 35:770-779.

17 Pamir MN: How to write an experimental research paper. Acta Neurochir Suppl 2002;83: 109-113. 